\title{
GEOID DETERMINATION FOR THE AREA OF POLAND BY THE LEAST SQUARES MODIFICATION OF STOKES' FORMULA
}

\author{
Joanna KUCZYNSKA-SIEHIEN*, Adam LYSZKOWICZ and Monika BIRYLO
}

University of Warmia and Mazury in Olsztyn, Oczapowskiego 1,10-719 Olsztyn, Poland

*Corresponding author's e-mail: joanna.kuczynska@uwm.edu.pl

\begin{tabular}{l} 
ARTICLE INFO \\
\hline Article history: \\
Received 10 February 2015 \\
Accepted 13 July 2015 \\
Available online17 September 2015 \\
\hline
\end{tabular}

Keywords:

KTH method of geoid modelling

Rgional geoid determination

Stokes integral

\begin{abstract}
Previous geoid/quasigeoid models calculated for the area of Poland were based on the traditional "remove-compute-restore" procedure. One of the modifications of this method is the least squares modification of Stokes' formula with additive corrections method (LSMSA), which was developed at the Royal Institute of Technology (KTH) in Stockholm in Sweden. The modified Stokes integral combines the regional terrestrial gravity data with a global geopotential model (GGM) giving the approximate geoid heights. To obtain the gravimetric geoid, four additive corrections, topographic, downward continuation, atmospheric and ellipsoidal, are calculated and applied.

This paper presents the results of computation of a new gravimetric geoid model for Poland using the KTH method. In computations terrestrial gravity anomalies derived from nine different gravimetric data sets, global geopotential model EGM2008 and global elevation data SRTM v. 4.1 were used. The determined gravimetric geoid model was evaluated with GPS/levelling points of the Polish ASG-EUPOS network. After fitting the geoid model to the GPS/levelling data using a 7-parameter model, the standard deviation of differences was estimated to $2 \mathrm{~cm}$.
\end{abstract}

\section{INTRODUCTION}

Geoid model determination is a crucial challenge in the development of the Earth sciences. Knowledge of the precise geoid model contributes to the study of the Earth's interior, long-term geophysical processes and is used in oceanography. An accurate regional geoid model, in particular, enables the user in many cases to replace the traditional height determination techniques by faster and more cost-effective GPSlevelling.

In Poland, over the years, a number of geoid/quasigeoid models were calculated based on different methods. The first regional astro-gravimetric geoid model for Poland was developed in 1961 (Bokun, 1961), whereas the last astro-gravimetric geoid model was computed in 2005 on the basis of corrected astro-geodetic and astro-gravimetric deflections of the vertical (Rogowski et al., 2005). The first gravimetric geoid model for the region of Central Europe, including Poland, was computed by (Tanni, 1949). The first gravimetric geoid model for Poland (geoid92) was calculated at the Department of Planetary Geodesy in Warsaw in 1993. To compute this geoid the least squares collocation combined with the integral method was used (Lyszkowicz, 1993). It is estimated that the accuracy of this geoid model is of the order of $\pm 26 \mathrm{~cm}$ (Lyszkowicz, 1993).

Further gravimetric quasigeoid models were calculated using technique "remove-compute-restore" according to the formula

$N=N_{G M}+N_{\Delta g}+N_{H}$ where the term $N_{G M}$ reflects the contribution of the geopotential model coefficients, while $N_{\Delta g}$ represents the contribution of the Faye'a anomalies $(\Delta g)$ after removing the effects of the geopotential model. The term $N_{H}$ is called the indirect effect on the geoid, and accounts for the change of equipotential surface after the terrain reduction is applied to $\Delta g$. The term $N_{\Delta g}$ can be calculated using the Fast Fourier Transform or the least squares collocation method (Lyszkowicz, 2012; Kryński, 2007). Accuracy of the last quasigeoid model computed from gravimetric data and geopotential model EGM08 by the collocation method after fitting to the vertical reference height system in Poland is accurate to $\pm 1.4 \mathrm{~cm}$ (Lyszkowicz, 2010).

But at the same time, there are no geoid models for Poland computed using the LSMSA method (least squares modification of Stokes' formula with additive corrections). In order to determine the next geoid model for Poland, this method was used in this paper. The method was developed at the Royal Institute of Technology (KTH) in Stockholm and is also known as the KTH method. This method was successfully applied for a gravimetric geoid determination in several countries. The results of the regional geoid modelling using the $\mathrm{KTH}$ method were given among others in (Ågren, 2004; Ellmann, 2004; Kiamehr, 2006; Abdalla 2009; Ulotu, 2009; Ågren et al., 2009; Daras et al., 2010).

The KTH method utilizes the least squares modification of the Stokes integral for the biased, unbiased, and optimum stochastic solutions. The principle of this modification is to match errors within 
terrestrial gravity data and the global geopotential model (GGM) omission and commission errors by means of the least squares. In the method the satelliteonly GGM are using what is discussed, for example, at work (Vaníček and Sjöberg, 1991). The main difference between the KTH method and other approaches to the gravimetric geoid determination comes from a different treatment of the gravity corrections. In conventional Stokesian approaches, the observed gravity anomalies are first corrected for the topographic and atmospheric gravitational effects and then reduced to the geoid surface. In the KTH method, the Stokes integration is applied directly to the gravity anomaly data. The complete contribution of the direct and secondary indirect effects of topography and atmosphere on the gravity anomalies and consequently the primary indirect effects of topography and atmosphere on the geoid heights are treated as the combined topographic and atmospheric corrections applied to the approximate geoid heights (Sjöberg, 2003b). The contribution of the downward continuation of the gravity anomalies from the Earth's surface onto the geoid surface is added to the approximate geoid heights as the downward continuation correction. The geoid heights are also corrected due to the ellipsoidal approximation of the Earth's shape.

The KTH method is briefly discussed in Section 2. Description of the utilized data is given in Section 3. The geoid computation results are shown in Section 4. Section 5 gives the results of the computed geoid model validation using GPS/levelling data. Conclusions could be found in Section 6 .

\section{LSMSA METHOD}

The computational procedure for estimation of the geoid height $\widehat{N}$ using KTH method can be summarized by the following formula (Sjöberg, 2003b):

$$
\widehat{N}=\tilde{N}^{0}+\delta N_{c o m b}^{T o p o}+\delta N_{D W C}+\delta N_{c o m b}^{a}+\delta N_{e}
$$

where $\tilde{N}^{0}$ is the approximate geoid height, $\delta N_{\text {comb }}^{\text {Topo }}$ is the combined topographic correction, which includes the sum of the direct and indirect topographical effects on the geoid heights; $\delta N_{D W C}$ is the downward continuation correction, $\delta N_{\text {comb }}^{a}$ is the combined atmospheric correction, which includes the sum of the direct and indirect atmospherical effects, and $\delta N_{e}$ is the ellipsoidal correction for the spherical approximation of the geoid in Stokes' formula to ellipsoidal reference surface.

The approximate geoid height $\tilde{N}^{0}$ is calculated basing on modified Bruns-Stokes' formula (Sjöberg, 2003c):

$\tilde{N}^{0}=\frac{c}{2 \pi} \iint_{\sigma_{0}} S_{L}(\psi) \Delta g d \sigma+c \sum_{n=2}^{M} b_{n} \Delta g_{n}^{G G M}$

where the first term of the equation (3) contains modified Stokes' function $S_{L}(\psi)$ and is computed using Faye'a anomalies $\Delta g$ with the spherical cap $\sigma_{0}$, parameter $c=R / 2 \gamma_{0}$, where $R$ is the Earth's mean radius, and $\gamma_{0}$ is the mean normal gravity. The second term represents the Global Geopotential Model (GGM) contribution to the approximate geoid height and $\Delta g_{n}^{G G M}$ is the Laplace spherical harmonics of the gravity anomaly calculated from the GGM of degree $n, M$ is the maximum degree of GGM, $b_{n}$ is the leastsquares modification parameters.

Precise geoid height is obtained by applying four additive corrections. The combined topographic effect $\delta N_{\text {comb }}^{\text {Topo }}$ is the sum of the direct and indirect effects, and is calculated using formula (Sjöberg, 2000):

$\delta N_{c o m b}^{T o p o}=\delta N_{d i r}+N_{d i r} \simeq-\frac{2 \pi G p}{\gamma_{i}}\left[H^{2}+\frac{2}{3 R} H^{2}\right]$

where $\rho$ is the mean topographic mass density, $G$ is the gravitational constant, $\gamma_{l}$ is the normal gravity and $H$ is the orthometric height.

Downward continuation effect in the KTH method is computed applying following formulas:

$$
\begin{aligned}
& \delta N_{D W C}(P)=\delta N_{D W C}^{(1)}(P)+\delta N_{D W C}^{L 1, F a r}(P)+\delta N_{D W C}^{L 2}(P) \\
& \delta N_{D W C}^{(1)}(P)=H_{p}\left(\frac{\Delta g(P)}{\gamma}+3 \frac{\varsigma_{p}^{0}}{r_{p}}-\left.\frac{1}{2 \gamma} \frac{\partial \Delta g}{\partial r}\right|_{p} H_{p}\right) \\
& \delta N_{D W C}^{L 1, F a r}(P)=c \sum_{n=2}^{M}\left(s_{n}^{*}+Q_{n}^{M}\right)\left[\left(\frac{R}{r_{p}}\right)^{n+2}-1\right] \Delta g_{n}^{G G M}(P) \\
& \delta N_{D W C}^{L 2}(P)=\frac{c}{2 \pi} \iint_{\sigma_{0}} S_{L}(\psi)\left(\left.\frac{\partial \Delta g}{\partial r}\right|_{p}\right)\left(H_{p}-H_{Q}\right) d \sigma_{Q}
\end{aligned}
$$

where $P$ is the computation point, $\varsigma_{p}^{0}$ is an approximate value of the height anomaly and $Q$ is the running point in Stokes' integral, $r_{p}=R+H_{P}$, and $s_{n}^{*}=s_{n}$, if $2 \leq n \leq M$, otherwise $s_{n}^{*}=0, s_{n}$ is the modification parameter, see (Ågren, 2004). 
The combined atmospheric effect $\delta N_{\text {comb }}^{a}$ can be approximated using the equation:

$$
\delta N_{\text {comb }}^{a}=-\frac{2 \pi R \rho_{0}}{\gamma} \sum_{n=2}^{M}\left(\frac{2}{n-1}-s_{n}-Q_{n}^{L}\right) H_{n}-\frac{2 \pi R \rho_{0}}{\gamma} \sum_{n=M+1}^{\infty}\left(\frac{2}{n-1}-\frac{n+2}{2 n+1} Q_{n}^{L}\right) H_{n}
$$

where $\rho_{0}$ is the atmospheric density at sea level, and $H_{n}$ is the Laplace harmonic of degree $n$ for the topographic height.

The ellipsoidal correction $\delta N_{e}$ to the modified Stokes' formula takes the following form:

$$
\delta N_{e}=\frac{R}{2 \gamma} \sum_{n=2}^{\infty}\left(\frac{2}{n-1}-s_{n}^{*}-Q_{n}^{L}\right)\left(\frac{a-R}{R} \Delta g_{n}^{G G M}+\frac{a}{R}\left(\delta g_{e}\right)_{n}\right)
$$

where formula for $\left(\delta g_{e}\right)_{n}$ calculation with necessary coefficient explanation is given by (Sjöberg, 2004).

More details about the theoretical basis of the method, including computation of signal and noise degree variances, are presented e.g. by (Sjöberg, 1984, 1991, 2003a, 2003b, 2003c; Ellman, 2004; Daras, 2008; Ågren et al., 2009; Abdalla and Tenzer, 2011).

\section{DATA}

Gravimetric data used in this work consists of nine sets of gravity anomalies (Fig. 1) obtained from various sources and collected in the years from 1990 to 1995 at the Department of Planetary Geodesy at Space Research Centre in Warsaw (Łyszkowicz, 1994). The data from the Czech Republic, Slovakia, Hungary, Romania and Western Ukraine were probably developed in a consistent manner that is based on the Bouguer anomaly map, which assumes the density of the Earth's crust is equal to $2.67 \mathrm{~g} / \mathrm{cm}^{3}$. The mean gravity anomalies were probably created as the average values in the $5^{\prime} \times 7.5^{\prime}$ areas. The number of measurements in the block is not known. For these data information about the accuracy is also unknown. In contrast, gravity anomaly collections from the area of Poland are well-documented.

Land gravimetric measurements on Polish territory were made over the period 1957 - 1979 using Askania, Sharpe, Scintrex, Sodin and Worden gravimeters. In total, approximately $1,000,000$ points were measured with mean error of free-air gravity anomaly no greater than $\pm 0.5 \mu \mathrm{ms}^{-2}$ (Królikowski, 1994). The original anomalies have been converted to anomalies related to normal field of GRS80 ellipsoid and IGSN71 gravity reference level. Subsequently, these anomalies were interpolated on 1' x 1' grid nodes (Kryński, 2007, p. 135) and used in our geoid computation.

Sea gravimetric measurements on the southern part of Baltic Sea were carried out in $1978-1980$. The total number of measured points is 8,423 . The mean error of computed free-air gravity anomalies is estimated as $\pm 5.7 \mu \mathrm{ms}^{-2}$. On the basis of the measured point anomalies, 14,981 mean anomalies on 1' $x$ 1' grid nodes were interpolated. The accuracy of the mean marine anomaly is estimated to be $\pm 4 \mu \mathrm{ms}^{-2}$ (0.4 mGal) (Łyszkowicz, 1994).
All these gravimetric data were referred to the normal field defined by GRS80 ellipsoid and IGSN71 gravity reference level.

In order to determine the geoid using the $\mathrm{KTH}$ method, free-air gravity anomalies (Kryński, 2007) were interpolated by the least squares prediction method on $1.5^{\prime} \times 3.0^{\prime}$ grid nodes for the area $47^{\circ}<\varphi$ $<57^{\circ}$ and $11^{\circ}<\lambda<27^{\circ}$ (Fig. 1). The GRAVSOFT program geogrid.for (Forsberg and Tscherning, 2008) was applied for this task. The geogrid.for program uses covariance function parameters with variance $C_{0}$ and correlation length $\xi$ (Fig. 2). To determine these parameters from gravity data, empcov.for program was used. The obtained results are equal to $45600\left(\mu \mathrm{ms}^{-2}\right)^{2}$ for variance and $35.5,(65.8 \mathrm{~km})$ for correlation length.

As a result of interpolation, a set of 128,721 gravity anomalies were obtained. This set of gravity anomalies is characterized by a mean value $62.4 \mu \mathrm{ms}^{-2}$ (6.24 mGal) and a standard deviation $231.6 \mu \mathrm{ms}^{-2}$ (23.16 mGal).

In a new geoid model calculations global geopotential model EGM2008 was used. The results of evaluation tests have revealed that the EGM08 model is very accurate over all existing geopotential models for the area of Poland (Lyszkowicz, 2009). EGM2008 is a spherical harmonic model of the Earth's gravitational potential, developed by a least squares combination of the ITG-GRACE03S gravitational model and its associated error covariance matrix, with the gravitational information obtained from a global set of area-mean free-air gravity anomalies defined on a 5 arc-minute equiangular grid (Pavlis et al., 2012).

SRTM data v. 4.1 was chosen as a digital elevation model (DEM) and used in the processing. The SRTM DEM has a resolution of $90 \mathrm{~m}$ at the equator, and are provided by the CGIAR-CSI GeoPortal for the entire world (http://srtm.csi.cgiar.org). The data are derived from the USGS/NASA SRTM data. Areas with regions of no data in the original SRTM data have been filled using interpolation methods described by (Reuter et al., 2007). 
Table 1 Statistics of results (in $\mathrm{m}$ ).

\begin{tabular}{lrrrc}
\hline & Minimum & \multicolumn{1}{c}{ Maximum } & Mean & Standard Deviation \\
\hline Approximate geoid height $\tilde{N}^{0}$ & 22.221 & 47.932 & 35.389 & 6.654 \\
Combined topographic correction & -5.325 & 0.006 & -0.082 & 0.181 \\
Downward continuation correction & -0.027 & 0.216 & 0.003 & 0.010 \\
Atmospheric correction & -0.002 & 0.002 & 0.001 & 0.001 \\
Ellipsoidal correction & 0.000 & 0.003 & 0.001 & 0.000 \\
\hline
\end{tabular}

The obtained geoid model was evaluated using the ASG-EUPOS network. It is a network of permanent GNSS stations established for surveying practice and has been operating fully since 2008. The network is based on 98 reference stations situated in Poland and 22 foreign stations. The complete set of coordinates of the domestic reference stations of the ASG-EUPOS system used in this paper are in ETRF2000 coordinate system and was downloaded from the website www.asgeupos.pl. The ellipsoidal heights of the network points were determined with an accuracy of $1 \mathrm{~cm}$. The normal heights of these points were determined in the Kronsztadt 86 datum by connecting them to the national precise levelling network.

\section{GEOID COMPUTATION AND RESULTS}

Based on Eq. 2, approximate geoid height $\tilde{N}^{0}$ was calculated in $1.5^{\prime} \times 3.0^{\prime}$ grid. The South-West corner of the target area grid has $\varphi=48^{\circ}$ and $\lambda=12^{\circ}$, while the North-East has $\varphi=56^{\circ}$ and $\lambda=26^{\circ}$. In computation EGM2008 model was used up to degree 360. The part of the determined geoid from terrestrial gravity data is shown on the left side of Figure 3, whereas the part of the determined geoid from GGM on the right side. By adding the two foregoing grid files we got the approximate geoid height which was ready for applying correction terms.

The KTH technique for geoid adds the direct and indirect effects on the geoid heights giving the combined topographic correction, which was obtained using Eq. 4. Moreover, topographic effects is also connected with a downward continuation correction, which is used to reduce gravity data located at surface of the Earth to sea level (approximated by a sphere) to be consistent with Stokes formula. The downward continuation correction was computed according to Eq. 5. Topographic heights, necessary to compute both corrections were interpolated from SRTM data v. 4.1 (see Sect. 3). In the downward continuation correction calculations EGM2008 with $M=360$ was involved. The magnitude of the combined topographic correction is illustrated on the left side of Figure 4, whereas downward continuation correction on the right side. It is clear that the topographic effects are large in the mountainous areas in the Southern part of Poland. In the lowlands, the downward continuation corrections are at the $1-\mathrm{cm}$ level. The combined topographic effect is very significant, reaching a few meters for the highest part of the mountain. However, part of this effect is counteracted by the downward continuation effect.
The calculated combined atmospheric correction and ellipsoidal correction are illustrated respectively in Figure 5. Combined atmospheric correction is computed using Eq. 9, whereas ellipsoidal correction using Eq. 10. The aforementioned additive corrections depend on the modification method, cap size and maximum degree of the GGM being used. The maximum degree of the GGM is still $M=360$. Both the atmospheric and ellipsoidal corrections are of the order of millimeters and are almost not significant.

The last step in the geoid height $\widehat{N}$ computation using LSMSA method is adding up all the parts calculated in the previous steps according to Eq. 2. Results are illustrated in Figure 6. Evaluation of the computed gravimetric geoid model is described in the next section.

The full statistics of the above constituencies of Eq. 2 is given in Table 1.

\section{EVALUATION OF THE COMPUTED GRAVIMETRIC GEOID MODEL}

Currently, evaluation of the accuracy of calculated geoid models is realized by their comparison with the geoid spacing computed from independent data, that is from ellipsoidal heights obtained by GNSS measurements and orthometric heights $H$ from geometric levelling and gravity data.

In practice, due to the occurrence of various random and systematic errors in $h, H$ and $N$, the known relationship for each $i$ point

$h_{i}-H_{i}-N_{i}=0$

is not fulfilled, and we get

$h_{i}-H_{i}-N_{i}=\varepsilon_{i}$

The elimination of systematic factors $\varepsilon_{i}$ is necessary in order to properly assess the calculated geoid model. This task can be accomplished by least squares method using the extended observation equation

$\mathbf{a}_{i}^{T} \mathbf{x}=\varepsilon_{i}+v_{i}$

in which additional parameters (nuisance) $\boldsymbol{x}$ and the vector of coefficients $\mathbf{a}_{i}$ dependent on the spatial point position were introduced. Examples of parametric models, which were used to describe systematic factors in a mixed set of geometric, orthometric heights and geoid-ellipsoid separations, can be found in the paper (Fotopoulos, 2003). 
Selected models used in this work are given by Eqs. 14-16. The model based on the general 7-parameter similarity datum shift transformation with the simplified classic 4-parameter model is given by (Heiskanen and Moritz, 1967, chapter 5)

$\mathbf{a}_{i}^{T} \mathbf{x}=x_{0}+x_{1} \cos \phi_{i} \cos \lambda_{i}+x_{2} \cos \phi_{i} \sin \lambda_{i}+x_{3} \sin \phi_{i}+v_{i}$

An extended version of the above model is given with the inclusion of a fifth parameter as follows:

$\mathbf{a}_{i}^{T} \mathbf{x}=x_{0}+x_{1} \cos \phi_{i} \cos \lambda_{i}+x_{2} \cos \phi_{i} \sin \lambda_{i}+x_{3} \sin \phi_{i}+x_{4} \sin ^{2} \phi_{i}+v_{i}$

Recently, a more complicated form of the differential similarity transformation model was developed and tested in the Canadian region and is given by (Fotopoulos, 2003):

$$
\begin{aligned}
\mathbf{a}_{i}^{T} \mathbf{x} & =x_{1} \cos \phi_{i} \cos \lambda_{i}+x_{2} \cos \phi_{i} \sin \lambda_{i}+x_{3} \sin \phi_{i}+x_{4}\left(\frac{\sin \phi_{i} \cos \phi_{i} \sin \lambda_{i}}{W}\right)+ \\
& +x_{5}\left(\frac{\sin \phi_{i} \cos \phi_{i} \cos \lambda_{i}}{W}\right)+x_{6}\left(\frac{1-f^{2} \sin ^{2} \phi_{i}}{W}\right)+x_{7}\left(\frac{\sin ^{2} \phi_{i}}{W}\right)
\end{aligned}
$$

where $W=\sqrt{1-e^{2} \sin ^{2} \phi_{i}}, e^{2}$ is the eccentricity and $f$ is the flattening of the reference ellipsoid.

Testing the geoid model calculated by $\mathrm{KTH}$ method was conducted on the GNSS/levelling stations of ASG-EUPOS network. Normal heights of this network points are defined in the Kronsztadt 86 height system. In order to correctly calculate the $\Delta N_{i}$ differences, normal heights were converted to orthometric heights according to the formula

$H=H^{N}-\frac{\Delta g_{B}}{\gamma} H^{N}$

Computed corrections, second term in Eq. 15, on the territory of Poland are in the range from $-39 \mathrm{~mm}$ to $3 \mathrm{~mm}$.

After testing several models, the 7-parameter model (Fotopoulos, 2003) gave a slightly better fit then the 5- parameter model (Table 2) of the new gravimetric geoid with standard deviation equal to $22.5 \mathrm{~mm}$, and it was chosen for implementation.

\section{SUMMARY}

The new gravimetric geoid for Poland was determined using the KTH method. The geoid computation process consists of two principal numerical steps. First, the approximate geoid heights were computed using the modified Stokes' integral combined regional terrestrial gravity anomalies and EGM2008 model coefficients. The gravimetric geoid heights were obtained after applying four additive corrections: for the effects of the topography, atmosphere, downward continuation reduction, and spherical approximation. The magnitudes of the atmospheric and ellipsoidal corrections are very small as opposed to the corrections connected with topography effects, which are significant.

The determined gravimetric geoid model was evaluated with GPS/levelling points of the Polish ASG-EUPOS network. After fitting the geoid model to the GPS/levelling data using a 7-parameter model, the standard deviation of differences was estimated to
Table 2 Gravimetric geoid height and GPS/levelling data agreement.

\begin{tabular}{lc}
\hline \multicolumn{1}{c}{ Model } & Standard deviation $[\mathrm{cm}]$ \\
\hline before fitting & 3.1 \\
4-parametr & 2.6 \\
5-parameter & 2.3 \\
7-parametr & 2.2 \\
\hline
\end{tabular}

$2 \mathrm{~cm}$. The achieved accuracy is comparable with the accuracy of the last quasigeoid models computed for Poland using the remove-compute-restore method.

\section{REFERENCES}

Abdalla, A.: 2009, Determination of a gravimetric geoid model of Sudan using the KTH method: MSc. Thesis in Geodesy. Royal Institute of Technology, Stockholm, Sweden.

Abdalla, A. and Tenzer, R.: 2011, The evaluation of the New Zealand's geoid model using the KTH method. Geodesy and Cartography, 37, 1, 5-14. DOI: $10.3846 / 13921541.2011 .558326$

Ågren, J.: 2004, Regional geoid determination methods for the era of satellite gravimetry. Doctoral Dissertation in Geodesy, Royal Institute of Technology, Stockholm, Sweden.

Ågren, J., Sjöberg, L.E. and Kiamehr, R.: 2009, Computation of the gravimetric geoid model over Sweden using the KTH method. J. Appl. Geod., 3, $143-153$.

Bokun, J.: 1961, Astro-gravimetric geoid determination referred to Krassovski's ellipsoid in the area of Poland. Proceedings of the Institute of Geodesy and Cartography, VIII, z.1, (in Polish).

Daras, I.: 2008, Determination of a gravimetric geoid model of Greece using the method of KTH. MSc Thesis in Geodesy, Royal Institute of Technology, Stockholm, Sweden.

Daras, I., Fan, H., Papazissi, K. and Fairhead, J.D.: 2010, Determination of a gravimetric geoid model of Greece using the method of KTH, gravity, geoid and Earth observation. Proceedings of the International 
Association of Geodesy, 135, S. P. Mertikas, Ed., 407-413.

Ellmann, A.: 2004, The geoid for the Baltic countries determined by the least squares modification of Stokes' formula. Doctoral Dissertation in Geodesy, Report No. 1061, Royal Institute of Technology, Stockholm, Sweden.

Forsberg, R. and Tscherning, C.C.: 2008, An Overview Manual for the GRAVSOFT Geodetic Gravity Field Modelling Programs. $2^{\text {nd }}$ edition, Technical University of Copenhagen.

Fotopoulos, G.: 2003, An analysis on the optimal combination of geoid, orthometric and ellipsoidal height data. PhD Thesis, University of Calgary.

Heiskanen, W. and Moritz, H.: 1967, Physical Geodesy. W. H. Freeman and Co., New York, London and San Francisco.

Kiamehr, R.: 2006, Hybrid precise gravimetric geoid model for Iran based on recent GRACE and STRM data and the least squares modification of Stokes formula. J. Physics of Earth and Space, 32(1), 7-23.

Królikowski, Cz.: 1994, Explanations to the Polish gravimetric map 1:200000. Polish Geological Institute, Warsaw, (in Polish).

Kryński, J.: 2007, Precise modelling of the quasi-geoid for the area of Poland - the results and assessment of accuracy. Institute of Geodesy and Cartography, Monograph No. 13, (in Polish).

Łyszkowicz, A.: 1993, New Geoid Solution for the Area of Poland Using FFT. Paper presented at the II-nd Conference of Section C - Geodesy of the Central European Initiative Committee of Earth Sciences, May 11 - 14, 1993, Książ, Poland.

Łyszkowicz, A.: 1994, Description of the algorithm of the geoid investigation on Polish territory, height and gravimetric data, gravimetric databáze. Report, No. 11, Space Research Centre PAS, (in Polish).

Łyszkowicz, A.: 2009, Assessment of accuracy of EGM08 model over the area of Poland. Technical Reports, 12, 118-134. DOI: 10.2478/v10022-009-011-x

Łyszkowicz, A.: 2010, Quasigeoid for the area of Poland computed by least squares collocation. Technical Sciences, No. 13, 147-163. DOI: $10.2478 / \mathrm{v} 10022-010-0014-7$

Łyszkowicz, A.: 2012, Geoid in the area of Poland in author's investigations. Technical Sciences, No 15(1), 51-66.

Pavlis, N.K., Holmes, S.A., Kenyon, S.C. and Factor, J.K.: 2012, The development and evaluation of the Earth Gravitational Model 2008 (EGM2008). Journal of Geophysical Research-Solid Earth, 117. DOI: $10.1029 / 2011$ JB008916
Reuter, H.I, Nelson, A. and Jarvis, A.: 2007, An evaluation of void filling interpolation methods for SRTM data. International Journal of Geographic Information Science, 21, 9, 983-1008. DOI: $10.1080 / 13658810601169899$

Rogowski, J.B., Bogusz, J., Kujawa, L. and Kłęk, M.: 2005, Development of the method and the creation of the astronomical-geodetic geoid model. Warsaw University of Technology, Report for Institute of Geodesy and Cartography, Warsaw, (in Polish).

Sjöberg, L.E.: 1984, Least squares modification of Stokes and Vening- Meinesz formulas by accounting for errors of truncation, potential coefficients and gravity data. The Dept of Geodesy Report, No. 27, University of Uppsala.

Sjöberg, L.E.: 1991, Refined least squares modification of Stokes formula. Manusc. Geod., 16, 367-375.

Sjöberg, L.E.: 2000, On the topographic effects by the StokesHelmert method of geoid and quasi-geoid determinations. J. Geod., 74(2), 255-268. DOI: $10.1007 / \mathrm{s} 001900050284$

Sjöberg, L.E.: 2003a, Improving modified Stokes formula by GOCE data. Boll. Geod. Sci. Aff., 61(3), 215-225.

Sjöberg, L.E.: 2003b, A computational scheme to model geoid by the modified Stokes formula without gravity reductions. J. Geod., 74, 255-268. DOI: $10.1007 / \mathrm{s} 00190-003-0338-1$

Sjöberg, L.E.: 2003c, A general model of modifying Stokes formula and its least squares solution. J. Geod., 77, 459-464. DOI: 10.1007/s00190-003-0346-1

Sjöberg, L.E.: 2004, A spherical harmonic representation of the ellipsoidal correction to the modified Stokes' formula. J. Geod., 78, 180-186. DOI: $10.1007 / \mathrm{s} 00190-004-0378-1$

Tanni, L.: 1949, The regional rise of the geoid in Central Europe. Annales Academiae Scientiarum Fennicae, Seria A, Helsinki.

Ulotu, P.: 2009, Geoid model of Tanzania from sparse and varying gravity data density by the KTH method. Doctoral Dissertation in Geodesy, Royal Institute of Technology, Stockholm, Sweden.

Vaniček, P. and Sjöberg, L.E.: 1991, Reformulation of Stokes's theory for higher than second-degree reference field and a modification of integration kernels. J. Geoph. Res., 96(B4), 6529-6539. DOI: $10.1029 / 90 J B 02782$ 

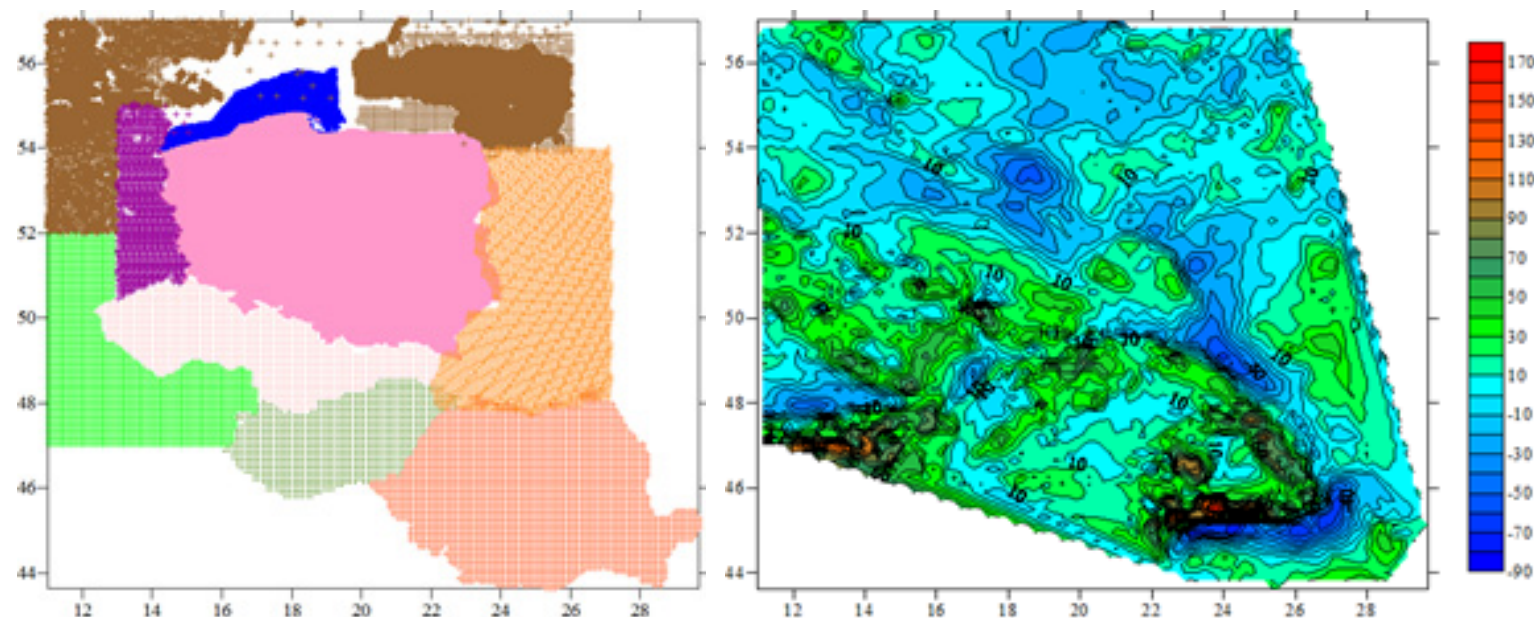

Fig. 1 Distribution of nine gravity anomalies sets and gravity anomalies map (in mGal) developed on their basis.
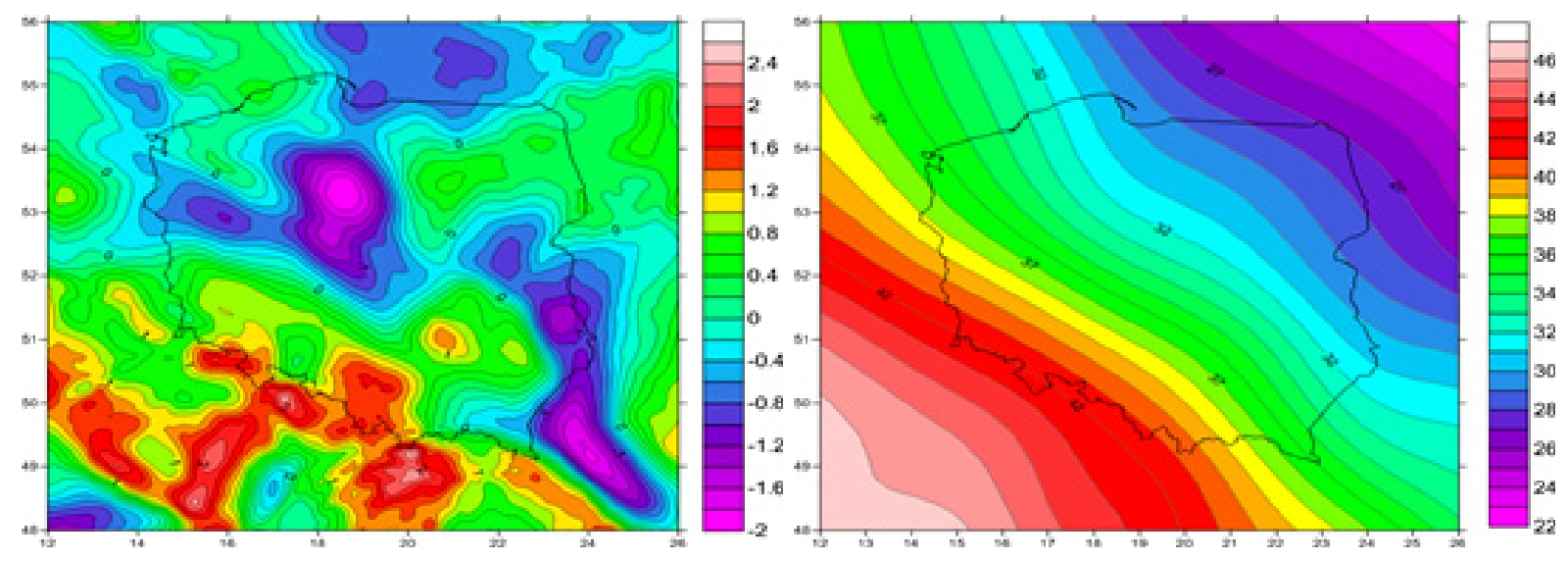

Fig. 3 Geoid determined from terrestrial gravity data and geoid computed from GGM model (in m).
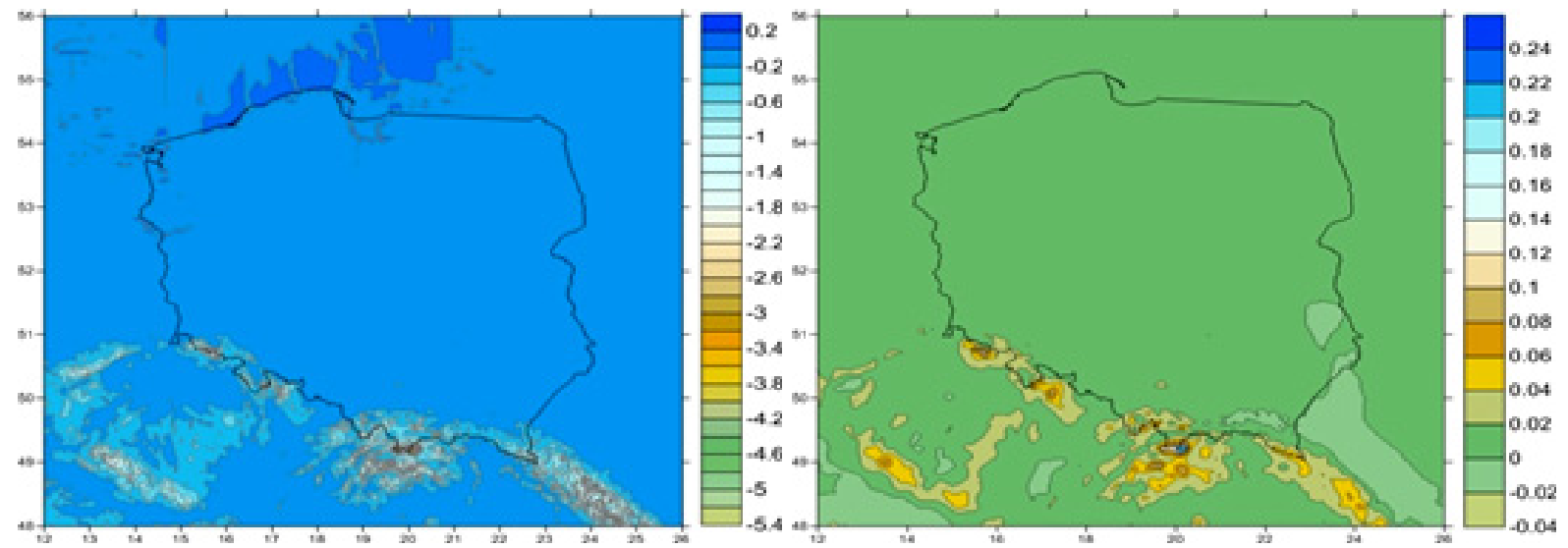

Fig. 4 The combined topographic correction and the downward continuation correction (in $\mathrm{m}$ ). 

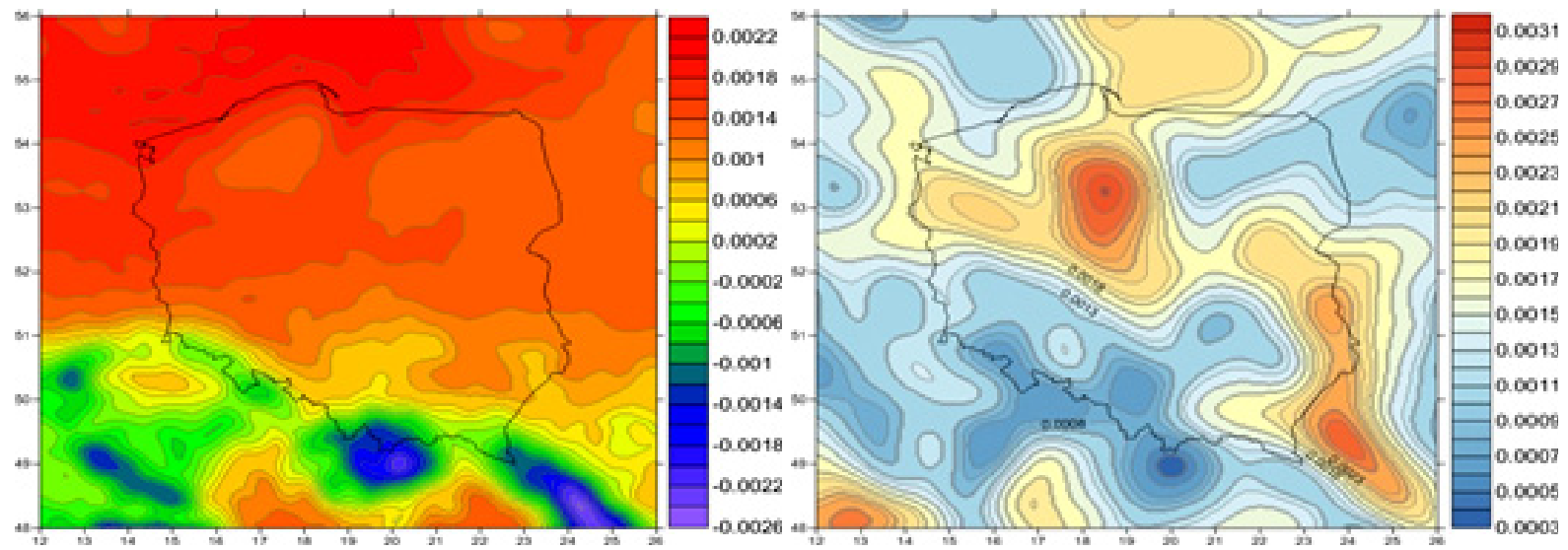

Fig. 5 The atmospheric correction and the ellipsoidal correction (in m).
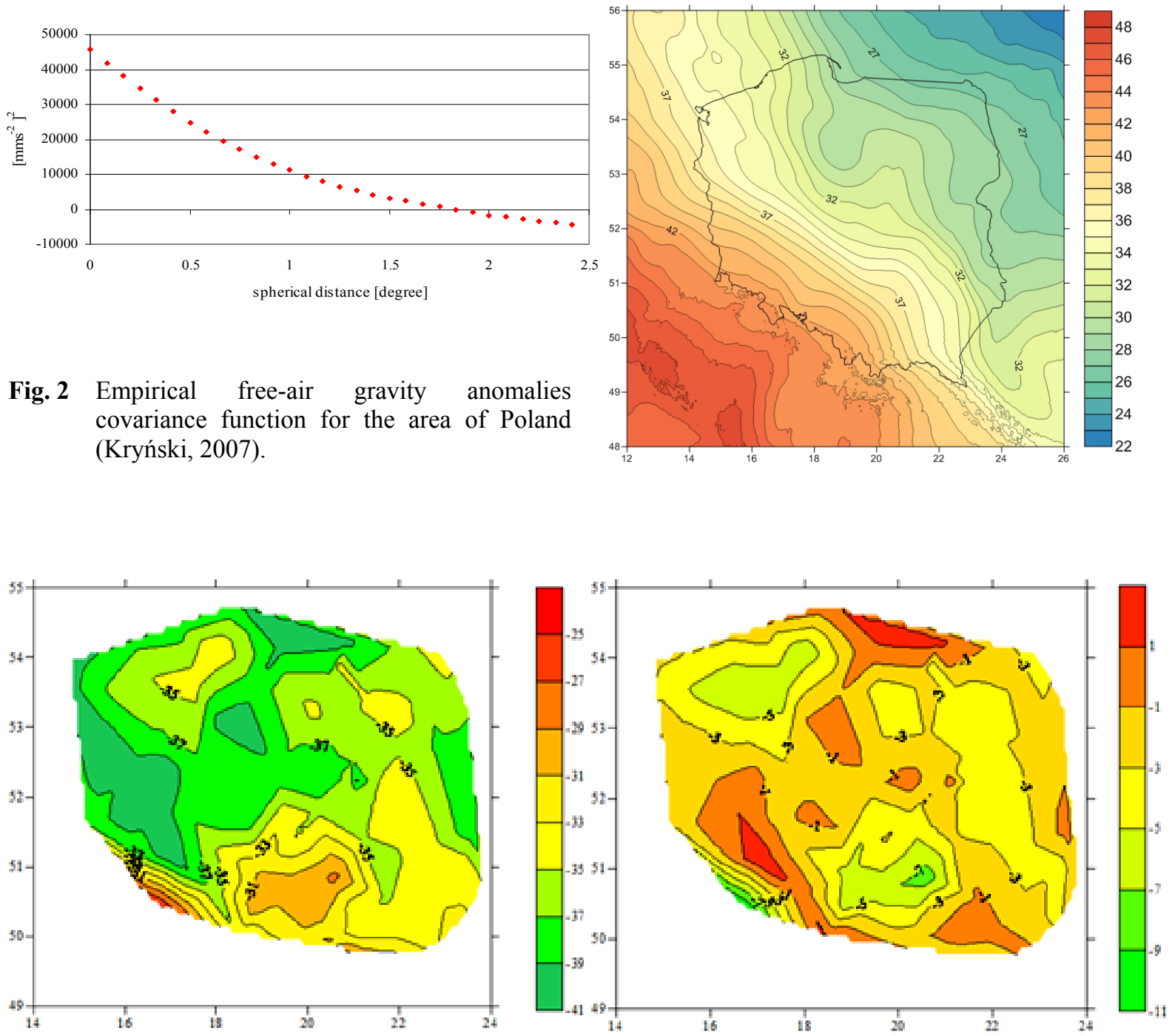

Fig. 7 Spatial distribution of $\Delta \mathrm{N}$ a) before and b) after fitting, on the territory of Poland (izolines in $\mathrm{cm}$ ). 